\title{
Advanced Characterization of HAZ Softening of AHSS for Crash Modeling
}

\author{
Hassan GHASSEMI-ARMAKI, ${ }^{1 / *}$ Elliot BIRO2) and Sriram SADAGOPAN ${ }^{1)}$ \\ 1) ArcelorMittal Global R\&D, 3001 E. Columbus Drive, E. Chicago, IN, 46312 USA. \\ 2) ArcelorMittal Global R\&D, 1390 Burlington St. E, Box 2460, Hamilton, Ont., L8P 2K5 Canada.
}

(Received on November 20, 2016; accepted on April 13, 2017; J-STAGE Advance published date: July $4,2017)$

\begin{abstract}
Advanced characterization of the mechanical properties in the softened HAZ is vital for designing welded AHSS components, as it is needed to predict post-weld performance, such as during crash. The weld heat affected zone (HAZ) of advanced high strength steels (AHSS) containing significant volume fractions of martensite exhibit considerable softening because of tempering effects. HAZ softening of two AHSS; Usibor 1500 (press hardening steel) and M1500 with nominal ultimate tensile strength (UTS) of $1500 \mathrm{MPa}$ has been characterized in this study. Samples were subjected to various rapid tempering cycles using the Gleeble to simulate the microstructures found in different locations of the sub-critical HAZ. Mechanical properties of simulated weld areas have been measured with different geometries, representing different levels of stress triaxiality. Furthermore, Digital Image Correlation (DIC), to determine fracture strain of HAZ, measured the fracture strain of a spot weld and base metal for Usibor 1500. Uniaxial tensile and notch sample geometries were used to investigate the influence of different strain path. The results show fracture strain is a weak function of strain path for samples that fail in the HAZ, whereas fracture strain of the base material considerably depends on strain path.
\end{abstract}

KEY WORDS: Heat Affected Zone (HAZ); Advanced High Strength Steels (AHSS); softening; FEA modeling; spot-welding.

\section{Introduction}

Currently, there is an extensive effort in the automotive industry to lower vehicle weight by using Advanced High Strength Steels (AHSS) to meet the new environmental regulations. AHSS are mainly used in body-In-white (BIW) applications with lower thickness to meet weight reduction targets while maintain structural performance. Press hardening steels (PHS) are a family of AHSS which are formed at high temperature and exhibit high strength at room temperature, owing to martensitic microstructure that forms during die quenching. Additionally, these steels have minimal springback at a relatively low cost. Spot welding is the most common joining process for automotive BIW structures due to its production convenience and cost effectiveness. ${ }^{1,2)}$ Spot-welding of PHS materials is accompanied by martensite tempering in the HAZ. Tempering of martensite is controlled by diffusion of alloying elements in the hierarchical structure of martensite. The mechanisms and kinetics of martensite tempering has been extensively reported elsewhere, ${ }^{3,4)}$ and Part I of this study has studied the modeling of tempering kinetics. ${ }^{5)}$

Tempering of martensite results in the reduction of hardness. The magnitude of the hardness drop depends on the

\footnotetext{
* Corresponding author: E-mail: hassan.ghassemi@arcelormittal.com DOI: http://dx.doi.org/10.2355/isijinternational.ISIJINT-2016-649
}

extent of HAZ tempering, and welding parameters, such as the maximum local temperature during welding. ${ }^{3-6)}$ In high strength steels, such as DP590, ${ }^{6)}$ there is minimal HAZ softening and the HAZ is not considered as separate area of elements in FEA modeling. However, in higher strength AHSS containing high volume fraction of martensite there is significant martensite tempering in the HAZ with large associated hardness changes across the weld. PHS and fully martensitic steels (e.g. M1500) with 100\% volume fraction of martensite show the highest HAZ softening, and the extent of softening depends on chemical composition. ${ }^{3,4)}$ Recently, FEA modeling of full car crash or components include a separate set of elements representing HAZ properties. Previously, the ratio of the strength of elements making up the weld HAZ compared to those representing the base material were calculated from hardness values to scale the material properties. ${ }^{7)}$ This scaling method represents the reduction in strength for $\mathrm{HAZ}$, but it equally reduces all mechanical properties, e.g. yield stress, UTS, and fracture strain, but, hardening exponent is kept constant. The scaling could predict the early initiation of crack in softened HAZ, but it's important also to predict the consequent failure of other softened HAZ areas during crash test in other stackups as well.

Spot-weld failure is modeled separately with solid element or beam element, where MAT_100 or MAT_100_DA are mostly used as available models in LS-DYNA. ${ }^{8}{ }^{-}$The 
overestimation or underestimation of HAZ failure can change the load path during crash loading and causes the overload or underload applied to spot-weld elements. Consequently, the scaling treatment of the HAZ can result in poor prediction of spot-weld failure, even if spot-weld failure model has been calibrated in different loading modes, and good failure surface has been input in FEA model. ${ }^{9)}$

There have been some studies reported in literature for characterization and fracture modeling of the HAZ in resistance spot welding for PHS. ${ }^{9-12)}$ Eller et al. has used asymmetric uniaxial, symmetric central hole tensile and bending specimens to study the effect of different cooling rate during hot-stamping and the consequent microstructure on failure load and strain localization in HAZ. They have found that under in-plane loading, strains localize in the softened HAZ, however, as base material hardness decreases, there is less strain localizing in the softened area of the HAZ. ${ }^{10)}$ Sommer et al. have simulated HAZ microstructure with Gleeble and measured fracture strain of different locations of microstructure in HAZ. Furthermore, they have divided the HAZ into different regions with fine solid element mesh $(\sim 0.1 \mathrm{~mm})$, and calibrated model with tensile specimen and 3-point bending. They could predict failure for element sizes of $1.5 \mathrm{~mm}$ and less, but did not get satisfying results for larger element sizes, and instead used purely phenomenological adjustment. $^{11,12)}$

In the present study, Gleeble specimens made out Usibor 1500 and M1500 materials have been tested in uniaxial tensile and notch geometries. Material properties, such as yield stress, ultimate tensile strength and strain hardening exponent, have been investigated as a function of softening extent. The modeling of softening kinetics and heat treatment parameters for generation of Gleeble specimens have been reported in Part I of this study. ${ }^{5)}$ In the second part of this study, symmetric tensile and notch specimens with spot weld were characterized for Usibor 1500 to investigate strain localization in HAZ and measure fracture strain in different strain paths. Finally, FEA modeling of cross-tension test was done to validate the fracture strain measured by welded samples.

\section{Materials \& Experimental Procedure}

$1.4 \mathrm{~mm}$ Usibor 1500 and $1.4 \mathrm{~mm} \mathrm{M1500} \mathrm{were} \mathrm{used}$ in this study to generate Gleeble specimens. Both steels have comparable ultimate tensile strength, $\sim 1600 \mathrm{MPa}$ for M1500 versus $1510 \mathrm{MPa}$ for Usibor 1500 . However, $0.2 \%$ offset yield stress (called yield stress hereafter) is $\sim 1370 \mathrm{MPa}$ for M1500, while it's $\sim 1050 \mathrm{MPa}$ for Usibor $1500 .{ }^{5)}$ Both steels contain fully martensitic microstructure, and major alloying elements of M1500 are $0.23 \mathrm{C}-0.38 \mathrm{Mn}-0.2 \mathrm{Si}$ and Usibor 1500 are $0.23 \mathrm{C}-1.18 \mathrm{Mn}-0.28 \mathrm{Si}, 0.2 \mathrm{Cr}, 0.001 \mathrm{~B}$. The AlSi coating of Usibor 1500 was removed from specimens using mechanical grinding to connect thermocouple wires for heat treatment using Gleeble. Therefore, the final thickness of the Usibor 1500 specimens was $\sim 1.3 \mathrm{~mm}$. The specimen size for Gleeble was $130 \mathrm{~mm}(\mathrm{RD}) \times 30 \mathrm{~mm}$. Uniformity of tempering in center of Gleeble specimens showed that a gauge length below $20 \mathrm{~mm}$ would be satisfactory for any geometry. ${ }^{5)}$ Uniaxial tensile and notch specimens were designed to measure mechanical properties of Gleeble speci- mens for different strain path resulting in different stress triaxiality values. Uniaxial tensile specimens have a gauge length of $10 \mathrm{~mm}$ and total length of $16 \mathrm{~mm}$ from points where the curvature of grip portion start. Notch specimens have a radius of $5 \mathrm{~mm}$ in center. Three tests were repeated for each geometry and Gleeble heat treatment condition.

To continue, $1.4 \mathrm{~mm}$ Usibor 1500 with AlSi coating was chosen to measure fracture strain of welded specimens. A Taylor Winfield 75-85 kVA AC spot welder was used to perform welding. The electrodes conformed to ISO Type $B$ with a face diameter of $6 \mathrm{~mm} .2$ pulses of 12 cycle time and 2 cycle cooling and 15 cycles holding time was used for welding of samples. Welds were cross-sectioned and the hardness measured using Vickers microhardness tester in accordance to AWS D8.9. ${ }^{13}$ ) The Usibor 1500 was welded to obtained nugget sizes of $5 \mathrm{~mm}$ and $7 \mathrm{~mm}$, as the minimum nugget size and nugget size close to expulsion, respectively. Nugget size was measured by rotation shear and it was confirmed that the nugget sizes were with a $\pm 0.1 \mathrm{~mm}$ tolerance.

Fracture strain measurements were carried out on each single sheet coupon with a spot-weld located at its center. Three different geometries representing different strain paths were designed; one customized uniaxial tensile specimens and two notch geometries. A gauge length of $20 \mathrm{~mm}$ was used for customized uniaxial tensile specimen, with the nugget in the center of specimen. Two notch geometries were designed, one cut with EDM, which had a notch radius of $5 \mathrm{~mm}$, and the other was punched and radius of $10 \mathrm{~mm}$. Also, fracture strain measurements were carried out on a welded sample that was not separated. The last sample design was used to study the effect of constraint from the nugget joining both sheets on strain path and fracture strain of softened HAZ. All specimens, including the Gleeble samples, were tested with MTS machine equipped with Correlated Solutions DIC system to measure strain within area of interest, and $2 \mathrm{~mm}$ gauge length was used for all strain measurements, unless otherwise noted.

Finally, LS-DYNA software was used to validate fracture strain measurement by welded samples for tensile samples and cross-tension loading mode using $3 \mathrm{~mm}$ mesh size for base metals and HAZ element. 1-Hex solid element connected to base material with Tied_Surface_to_Surface contact card was used. Since, there is no usually node equivalence between shell elements and solid element, this contact card transfers loads in 6 degrees, which can also include moments and torsion in weld failure. As well, this contact eliminates the need to have adjacent nodes at spot weld locations. ${ }^{8)}$

\section{Results \& Discussion}

\subsection{Evaluation of HAZ Using Gleeble Samples}

Figure 1 shows the hardness across welded zones for Usibor 1500 and M1500 after welding. As may be seen, the hardness drops in the sub-critical HAZ. For Usibor1500, the average hardness for base metal is $470 \mathrm{HV}$ and minimum hardness measured in the sub-critical HAZ is $295 \mathrm{HV}$, resulting in a maximum hardness drop of $175 \mathrm{HV}$. The HAZ microstructure has been simulated in four maximum temperatures, representing the HAZ microstructure. The 
detailed procedure used to recreate the HAZ properties has been published in detail in. ${ }^{5}$

Four Gleeble heat treatments were carried out on both the Usibor 1500 and M1500 materials. The average hardness of simulated materials has been shown in Table 1. The hardness values obtained from simulated materials were marked on the hardness profiles in Fig. 1 showing the locations in the weld HAZ that match the properties of the Gleeble tempered samples.

Figure 2(a) shows true stress vs true strain using the uniaxial tensile geometry for Usibor 1500 base metal and Gleeble heat treated materials. A gauge length of $2 \mathrm{~mm}$ was used to measure strain. Even after minor softening, when the hardness dropped to $\sim 450 \mathrm{HV}$ from a base material hardness of $\sim 470 \mathrm{HV}$, there is an obvious drop in strain hardening.

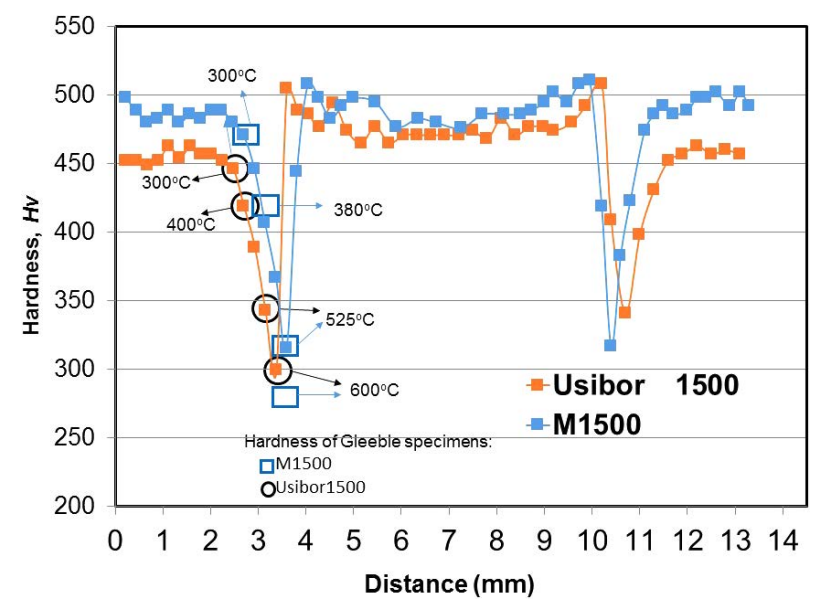

Fig. 1. Hardness of Usibor 1500 \& M1500 across base materials and welding zones after welding. (Online version in color.)

Table 1. Maximum Gleeble temperature $\left({ }^{\circ} \mathrm{C}\right)$ and average of hardness for Usibor 1500 and M1500 after heat treatment in Gleeble.

\begin{tabular}{ccc}
\hline $\begin{array}{c}\text { Max Gleeble } \\
\text { Temperature }\left({ }^{\circ} \mathrm{C}\right)\end{array}$ & $\begin{array}{c}\text { Hardness }(H V) ; \\
\text { Usibor } 1500\end{array}$ & $\begin{array}{c}\text { Hardness }(H V) ; \\
\text { M1500 }\end{array}$ \\
\hline 300 & 450 & 466 \\
400 & 425 & 423 \\
525 & 345 & 317 \\
600 & 295 & 290 \\
\hline
\end{tabular}

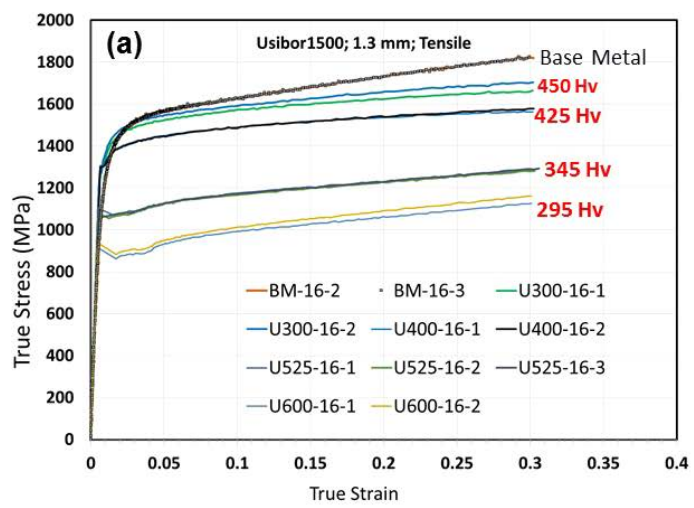

Increased tempering to hardness values of $\sim 295 \mathrm{HV}$ did not significantly reduce strain hardening further. Figure 2(b) shows a magnified area of Fig. 2(a) for strain up to 0.05 . It can be seen that when pulling the base material, strain hardening in the early stage of plastic deformation was high, whereas this high strain hardening in the early stage of deformation decreased with increased tempering temperature. Furthermore, the development of yield point elongation developed after significant tempering is observed. However, the stress-strain curves show non-linear dependency of yield stress from base metal to significant tempering. Yield stress increases for lower tempering temperature as compared to base material, then decreased with increasing tempering temperature.

Figure 3(a) shows the yield stress and UTS measured from Fig. 2 and those calculated based on hardness ratio of tempered material to base metal as a function of Gleeble specimen hardness for Usibor 1500 and base material hardness. If was found that the UTS decreases as tempering increases. The measured decrease in the UTS was comparable to the calculated drop in UTS based on the change in hardness of the materials. However, yielding onset measured from experimental data show that yielding onset actually increases when the material is first tempered, and then slowly decreases with further tempering. In addition, the yielding onset is considerably higher than is calculated by the hardness ratio. This confirms that the hardness ratio used for scaling the stress-strain behavior of HAZ elements, which is currently used for FEA modeling of spot-weld, $\left.{ }^{7}\right)$ does not represent the real mechanical behavior of the HAZ. Figure 3(b) shows the effective plastic strain at fracture as a function of hardness of the base metal and after tempering for the uniaxial tensile and notch geometries. The fracture strain increases with increasing tempering, and a considerable increase is obtained for Gleeble specimens with hardness values of $295 \mathrm{HV}$ and $345 \mathrm{HV}$. Fracture strain for the base metal and tempered microstructures at $300^{\circ} \mathrm{C}$ and $400^{\circ} \mathrm{C}$ is relatively similar. Figure 3 (b) shows that the difference between the fracture strains of the two geometries decreases with increasing tempering.

Figures 4(a) and 4(b) compare the true stress vs true strain of uniaxial tensile and notch samples for both materials heat treated at their respective three maximum temperatures; $400^{\circ} \mathrm{C}\left(380^{\circ} \mathrm{C}\right.$ for $\left.\mathrm{M} 1500\right), 525^{\circ} \mathrm{C}$ and $600^{\circ} \mathrm{C}$. As may be seen, M1500 shows lower yielding and flow stress at

Fig. 2. True stress as a function of true strain for $2 \mathrm{~mm}$ gauge length for uniaxial tensile specimens of Usibor 1500 (a) full curves and (b) up to 0.05 strain. (Online version in color.) 

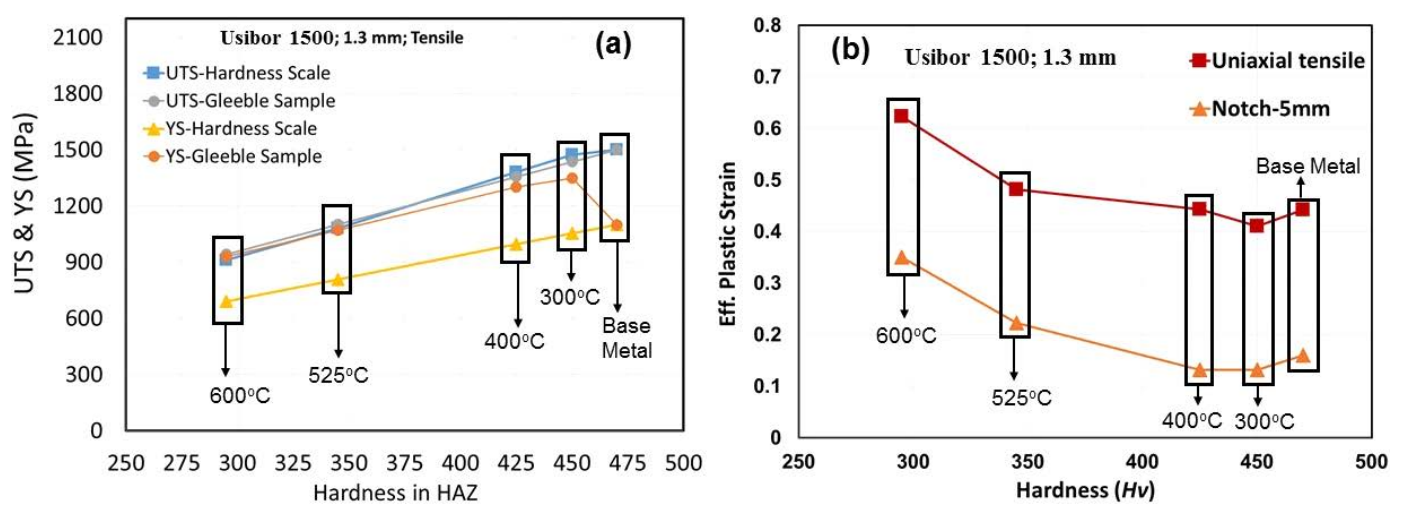

Fig. 3. For Usibor 1500 (a) Ultimate Tensile Strength (UTS), $0.2 \%$ offset yield stress (YS) calculated based on hardness scale and measured from Gleeble uniaxial tensile and (b) effective fracture strain as a function of hardness of Gleeble specimens corresponding to HAZ strength in different locations. (Online version in color.)
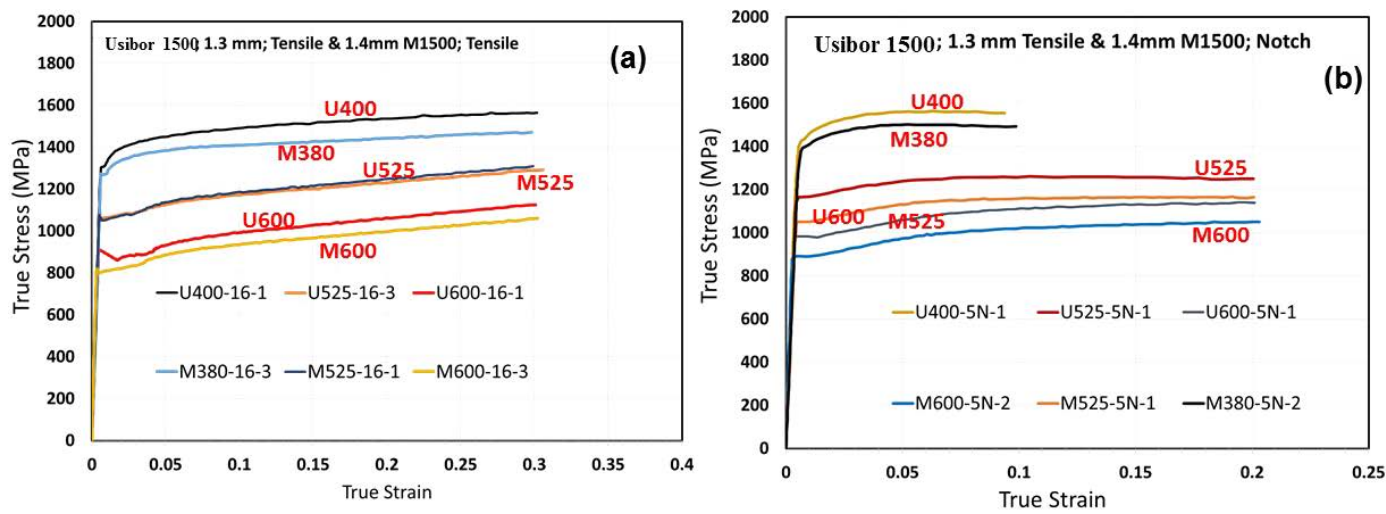

Fig. 4. True stress vs true strain for Usibor 1500 \& M1500 sheet steels after heat treatment in Gleeble at different temperatures (a) Uniaxial tensile and (b) Notch tests. (Online version in color.)

identical tempering temperatures when compared to Usibor 1500 , except for the uniaxial tensile mechanical properties of the samples tempered at $525^{\circ} \mathrm{C}$. The strain hardening is almost identical for both steels at all tempering temperatures. M1500 generally has a higher yielding strength ( 1 $370 \mathrm{MPa})$ and lower strain hardening as compared to Usibor 1500 with yielding strength of $\sim 1070 \mathrm{MPa}$. However, tempering of both materials at similar temperatures shows that the yield strength of M1500 relatively decreases and get less than Usibor 1500, while strain hardening of both steels is almost identical after tempering. This result highlights that tempering of two microstructures, M1500 and Usibor 1500, does not change mechanical properties of the two materials in an identical fashion. As found, the yield strength in the HAZ of M1500 will change significantly when compared to the yield strength in the HAZ of Usibor 1500, when compared to as-received condition. The yield strength of M1500 does not increase after tempering at high temperature, but this is not true for Usibor 1500. Understanding these changes is important for providing stress-strain data to FEA models. These differences between two steels shows that tempering kinetics of two steels at a certain peak temperature is not similar, and has been discussed in-detail somewhere else. ${ }^{5)}$

\subsection{Fracture Strain of Welded Samples vs Base Mate- rial}

While the measurement of stress-strain curves in different locations of the HAZ is necessary to predict yielding and strain hardening during deformation, the measured fracture strain of the Gleeble specimens is required to determine the appropriate mesh size need to predict fracture strain of discrete regions in the HAZ. Although, this is possible for modeling of spot-weld fracture in small FEA model, when modeling full vehicles to predict crash performance, the FEA mesh is made of relatively coarse shell elements, as compared to what is required for discrete HAZ. Therefore, the fracture strain, in this paper, has been measured in welded samples containing a fully realized weld zone with a fusion zone, HAZ, and base material.

Figure 5(a) shows a welded Usibor 1500 coupon, which has been separated from the second piece in the stackup by rotational shear method, called single-sheet sample hereafter. The rotational shear method applies a rotation to both coupons in the welded joint without bending them. Thus, the coupons can be separated without damaging either the base material or the HAZ. In cases where material was from the fractured nugget was proud of the single-sheet sample after separation, the additional material was gently polished to flatten the surface. The single-sheet sample has both the nugget and the HAZ located on the tensile coupon, but the second piece of the joint has been removed. However, to confirm the effect of nugget constraint on fracture strain, a complete weld (see Fig. 5(b)) was also tested, where the sheets were not separated after welding. The full weld sample was pulled from a longer piece and strain was measured on same side.

Figure 6(a) shows load-displacement curve for uniaxial 

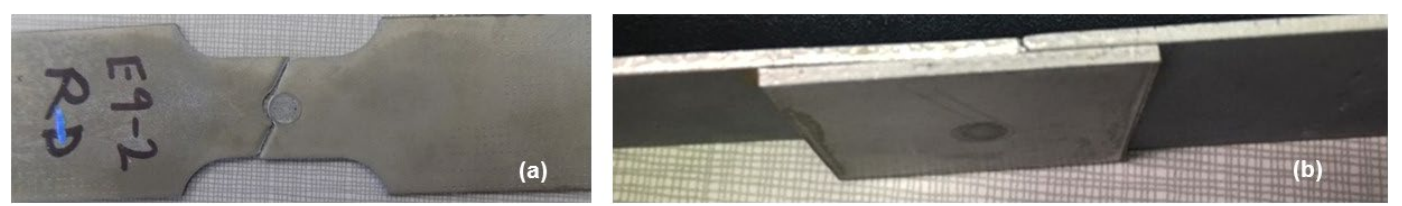

Fig. 5. (a) Welded samples (a) cut after homogenous stackup welding using rotation shear and (b) used as it is after welding. (Online version in color.)

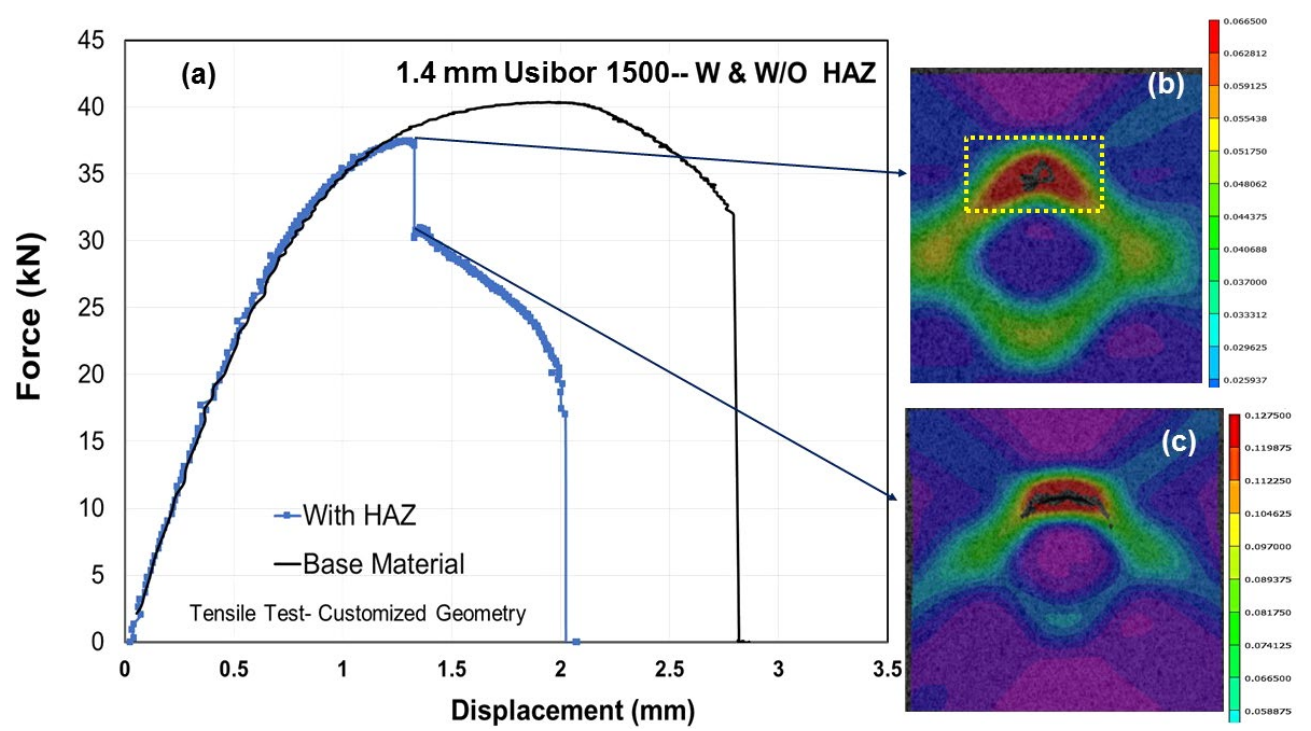

Fig. 6. (a) Force vs displacement of customized uniaxial tensile for Usibor 1500 based material and welded sample (Fig. 5(a)), (b) Major strain right before failure, and (c) after sharp force drop for welded sample. (Online version in color.)

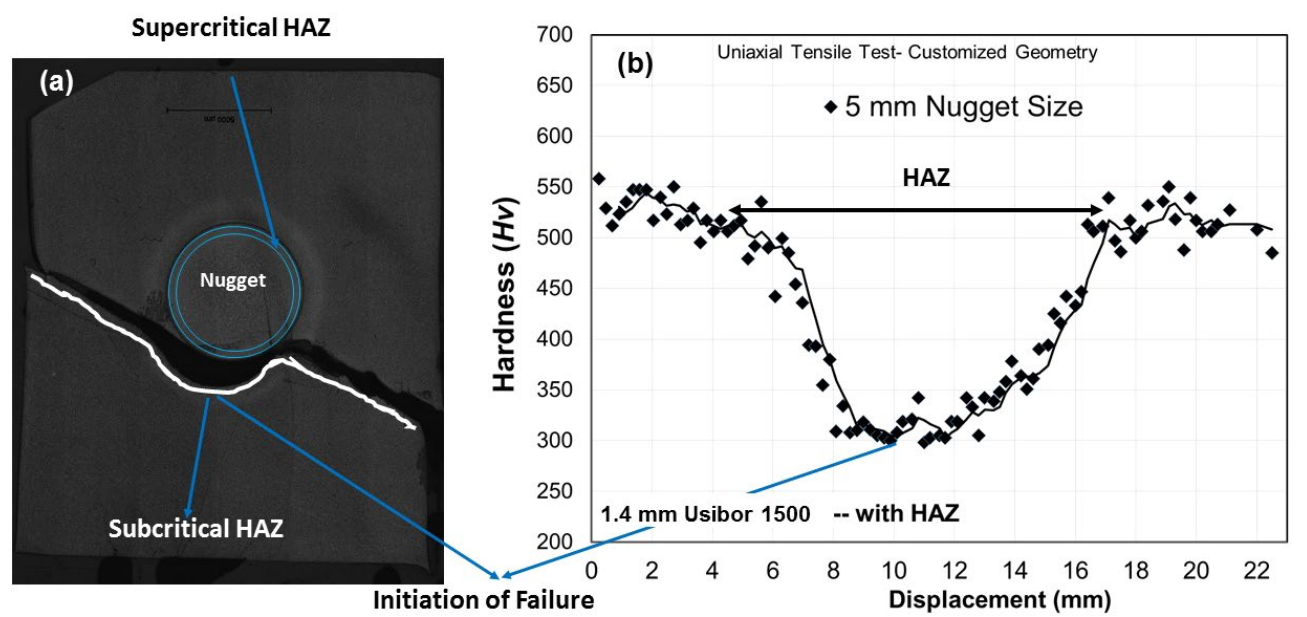

Fig. 7. (a) Optical image of tensile sample after failure (b) hardness across the path indicated by while line in (a). (Online version in color.)

tensile test of a single-sheet sample, both with and without welding (the welded sample has nugget size of $5 \mathrm{~mm}$ ). Figures 6(b) and 6(c) show the image captured by DIC camera right before failure initiation and after the sharp load drop, respectively. Strain is concentrated in the HAZ, where failure initiated, and caused a sharp drop in load. As loading continued, cracks propagated through the HAZ and base material. As seen in Fig. 1, the hardness gradient in the HAZ is sharp, and where failure has been initiated is an important information to understand the contribution of different regions of HAZ to failure. Therefore, as indicated by the white line in Fig. 7(a), hardness across the path of failure has been measured. Figure 7(b) shows the hardness value across this path, where the two ends of the curves fall within the base material, and center of curve where minimum hardness is observed corresponds to area indicated in Fig. 6(b) by dashed line. The internal ring in Fig. 7(b) is nugget area and outer ring is supercritical HAZ, and beyond that is subcritical HAZ. These results indicate that failure starts at subcritical HAZ where the minimum hardness after tempering occurs, which is $\sim 300 \mathrm{HV}$.

Figure 8(a) shows the nominal engineering stress and engineering strain for the $2 \mathrm{~mm}$ gauge length within HAZ, where strain is concentrated, and failure initiated. Since the thickness changes from the HAZ to the nugget (due to indentation), the nominal sheet thickness was used to calculate the nominal engineering stress. When the HAZ is present in welded sample (Fig. 5(b)) the ultimate tensile 

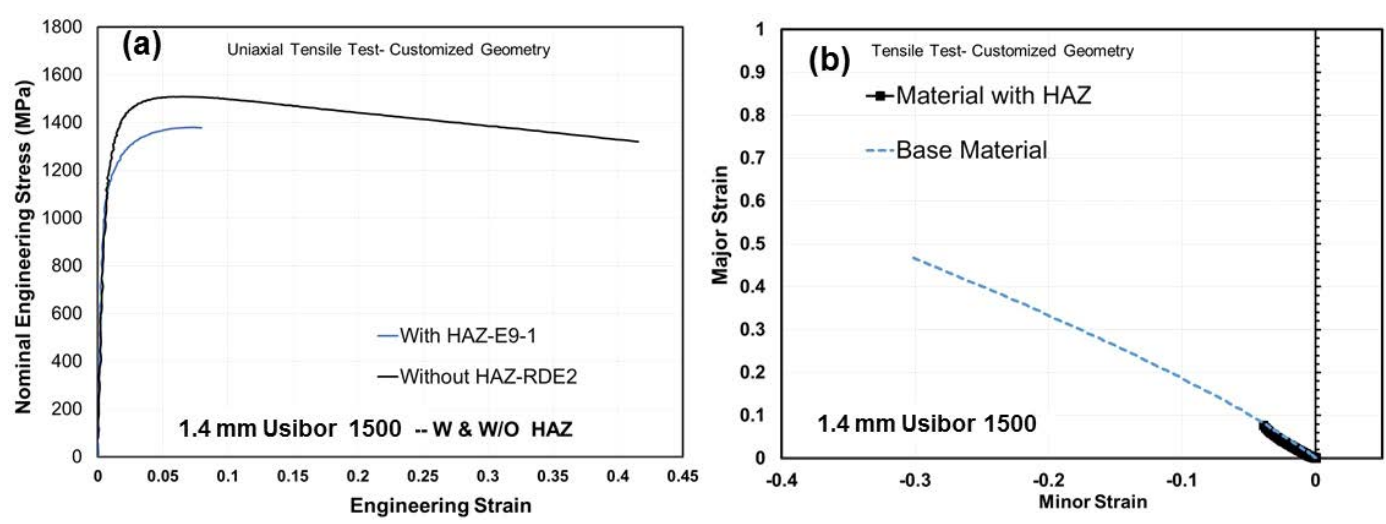

Fig. 8. (a) Nominal engineering stress vs engineering strain and (b) Major vs minor strain of customized uniaxial tensile for Usibor 1500 base material and welded sample (Fig. 5(a)). (Online version in color.)

Table 2. Major, minor, equivalent fracture strain and ratio of fracture strain measured for welded sample to base material of Usibor 1500. Strains were measured for $2 \mathrm{~mm}$ Gauge Length (G. L.) except the last row.

\begin{tabular}{ccclccc}
\hline \multirow{2}{*}{ Geometry } & Samples & Major Strain & Minor Strain & Strain Path $\left(\varepsilon_{2} / \varepsilon_{1}\right)$ & $\begin{array}{c}\text { Equ. Fracture } \\
\text { Strain }\end{array}$ & $\begin{array}{c}\text { Equ. Fracture } \\
\text { Strain of HAZ/BM }\end{array}$ \\
\hline \multirow{2}{*}{ Tensile } & Sample with HAZ & 0.0746 & -0.0357 & -0.48 & 0.0746 & 0.2 \\
& Base Material & 0.423 & -0.25 & -0.6 & 0.427 & - \\
\hline Notch-2 & Sample with HAZ & 0.059 & -0.00742 & -0.126 & 0.0642 & 0.37 \\
\hline \multirow{2}{*}{ Notch-1 } & Sample with HAZ & 0.0534 & -0.00337 & -0.063 & 0.0597 & 0.161 \\
\hline $\begin{array}{c}\text { Notch-1 } \\
3 \text { mm G.L. }\end{array}$ & Sample with HAZ & 0.036 & -0.0098 & -0.27 & 0.037 & - \\
\hline
\end{tabular}

stress decreased $\sim 150 \mathrm{MPa}$, while total elongation reduces significantly. Figure $8(\mathrm{~b})$ is major and minor strain for same gauge length and location. The strain path is almost identical for both the welded and non-welded specimens. However, the welded sample (containing a HAZ) failed at a lower strain than the base material sample. Figure $8(b)$ indicates that the fracture strain calculated for the welded sample tensile geometry can be considered as the fracture strain measured under uniaxial tensile strain path. Table 2 shows minor, major and equivalent plastic strain at fracture for base material (without any weld or HAZ) in a welded sample. For the tensile geometry, the equivalent fracture strain is 0.427 and 0.075 , for the base material and welded sample, respectively. When compared, the fracture strain of the sub-critical HAZ is about $80 \%$ less than the base material. The softened microstructure in the HAZ around nugget causes strain localization, resulting in premature failure as compared to base material without any softening zone. Although, UTS of the welded sample with HAZ is about $10 \%$ lower than the base material, due to HAZ softening (Fig. 8(a)), its effect on fracture strain is much more significant.

It has been reported that the fracture strain depends on strain path, and consequently stress triaxiality. ${ }^{10)}$ The notch sample was chosen so as to characterize fracture strain following a different strain path than the standard tensile geometry. Figures 9(a) and 9(c) show two different notch geometries, called Notch-1 and Notch-2 hereafter. Two geometries have different cutting radius, and Notch-1 samples have been cut by EDM and Notch-2 samples by punch. It has been shown that edge quality can affect fracture strain, and materials with punched edge exhibit failure initiation from edge, showing lower fracture strain than samples with higher quality edge preparation. ${ }^{14}$ Figures 9 (b) and 9(d) present the DIC images of the weld samples containing a HAZ just before failure initiation. Failure initiated in the HAZ and center of sample regardless of edge quality, and propagated through HAZ and base metal until full material separation was achieved. However, when the test was repeated with unwelded samples, the DIC results show the failure initiation from the sample edge for Notch-2 geometry. This is contrast to the Notch-1 geometry, where failure started far from edge. So, only the Notch-1 geometry was used for fracture strain measurement of base materials.

Figure 10(a) shows the major and minor strain in samples after welding as well as in the base material as a function of displacement. The major strains are measured in the direction of the loading axis and the minor strains are measured perpendicular to the loading axis (where the strains are numerically smaller than along the loading axis). Figure 10(c) shows the DIC pattern on the sample when cracking initiated in the HAZ ring which was used for the strain measurement. At low displacement, major strain for samples with HAZ are higher than in base metal samples, consequently, the final fracture strain for the welded samples are lower than the base material samples. Figure 10(b) shows major strain vs minor strain for welded and base material samples. Results show a consistent strain path for both samples, while samples with a HAZ fail at lower strain. Table 2 shows minor, major and equivalent fracture strain of Notch-1 geometry for welded samples and base materials, and Notch-2 geometry only for welded sample. Minor strain is close to zero for welded samples with a softened HAZ and strain path is close to plane strain. For the Notch-1 sample, 

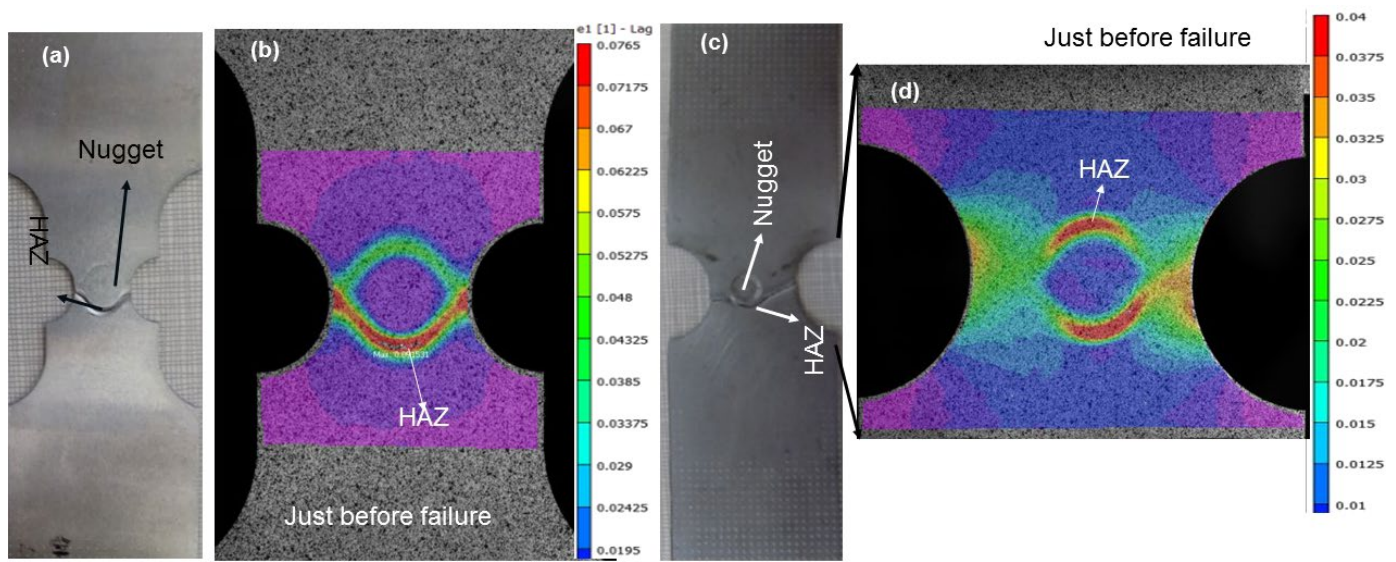

Fig. 9. Overview of notch tensile samples in welded coupons showing both the (a) sample overview and (b) DIC strain before failure in Notch-1, EDM machined with a $5 \mathrm{~mm}$ radius, and showing the (c) sample overview and (d) DIC strain before failure in Notch-2, punched with a $10 \mathrm{~mm}$ radius. (Online version in color.)
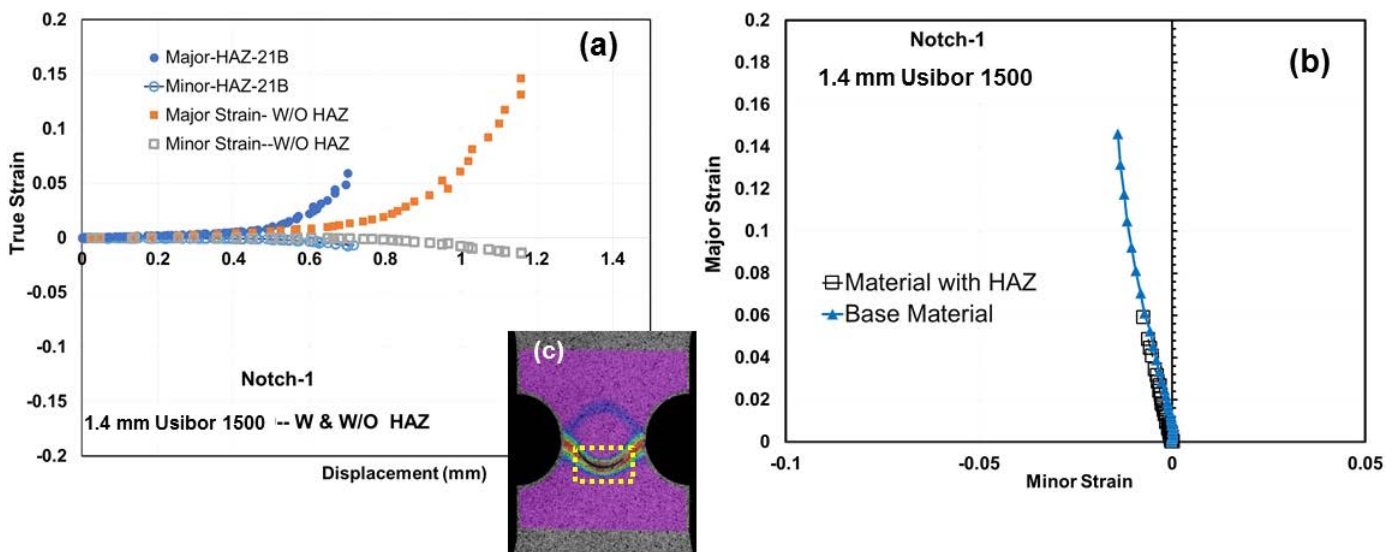

Fig. 10. (a) True strain vs displacement and (b) Major vs minor strain of Notch-1 geometry for Usibor 1500 based materials and welded sample (Fig. 5(a)), (c) Failure location within HAZ area. (Online version in color.)

the ratio of equivalent fracture strain of sample with HAZ to base material is 0.37 which is higher than the uniaxial tensile strain path which indicates the dependency of the "scaling" on loading mode.

Further tests were conducted by increasing the current to achieve a $7 \mathrm{~mm}$ nugget size. Fracture strain of this weld was measured both in the uniaxial and Notch-2 geometries. Figure 11 shows fracture strain as function of strain path for three kinds of tested samples; welded samples with two nugget sizes $(5 \mathrm{~mm}$ and $7 \mathrm{~mm}$ ) and the base material. The fracture strain of base material changes significantly with strain path. Conversely, it only changes slightly for welded samples. In fact, strain localization in the softened HAZ dominates the fracture strain rather than strain path. Furthermore, increasing nugget size slightly reduces fracture strain. Figure 12(a) shows the hardness across the failure path for both nugget sizes of $5 \mathrm{~mm}$ and $7 \mathrm{~mm}$ shown in Figs. 12(b) and 12(c). As seen, failure path is similar for both nugget sizes and failure location is in subcritical HAZ where minimum hardness is observed. Figure 12(a) shows that the hardness profiles across the HAZ portion of the fracture for both nugget sizes is almost identical, so the slight reduction in fracture strain can be contributed to geometry of HAZ around nugget. When the weld size increases, the HAZ geometry also changes. It may be seen that the HAZ is further from center of nugget in the $7 \mathrm{~mm}$, compared to the $5 \mathrm{~mm}$ weld, which may affect the stress state of the HAZ,

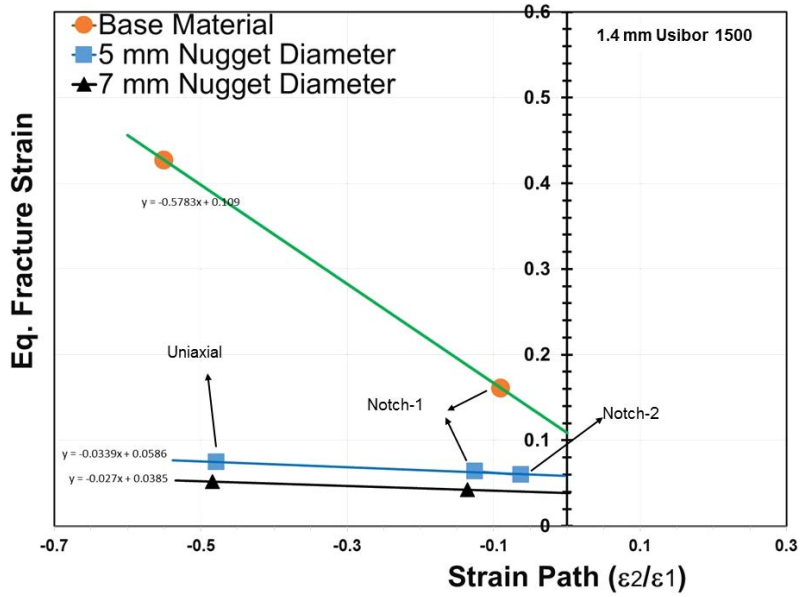

Fig. 11. Equivalent fracture strain as a function of strain path for base material, and $5 \mathrm{~mm} \& 7 \mathrm{~mm}$ nugget sizes. (Online version in color.)

resulting in strain concentration at a lower displacement. However, the difference in fracture strain of two nugget sizes $(7 \%)$ is negligible when compared to the difference between the fracture strain of the base material and welded samples. If a linear regression drawn through each data set, the fracture strain ratio of welded sample with $5 \mathrm{~mm}$ nugget size to base material for plane strain is 0.55 , while it's 0.2 for uniaxial tension strain path. As seen in Fig. 1, the ratio of minimum hardness in sub-critical HAZ (300 HV) to 

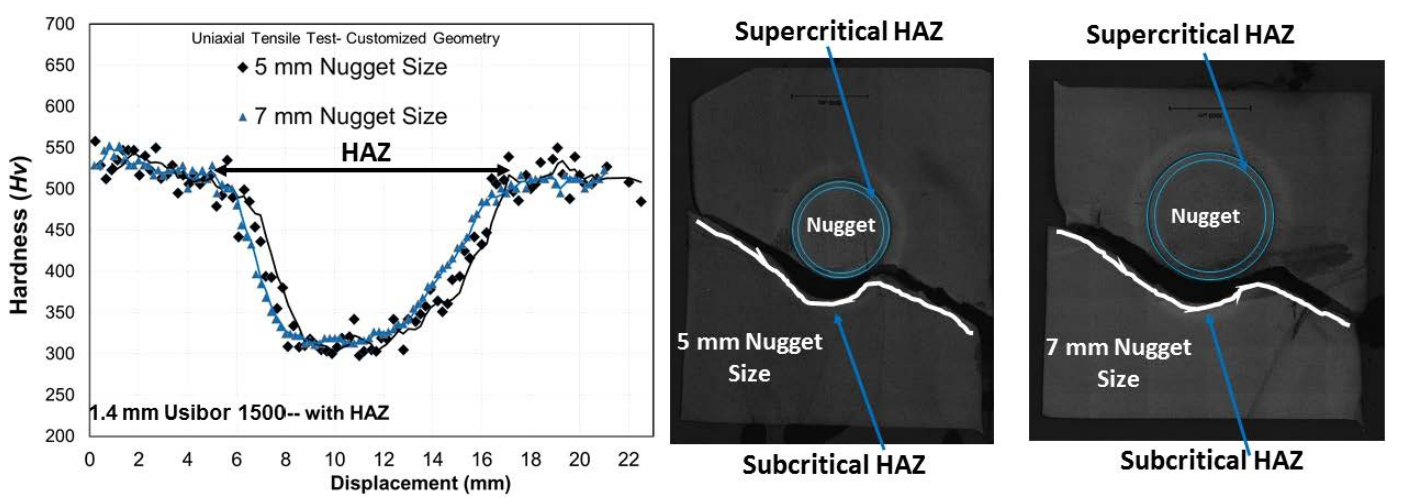

Fig. 12. (a) Hardness across the failure path for two nugget sizes, (b) and (c) optical image of $5 \mathrm{~mm}$ and $7 \mathrm{~mm}$ nugget size, respectively. (Online version in color.)
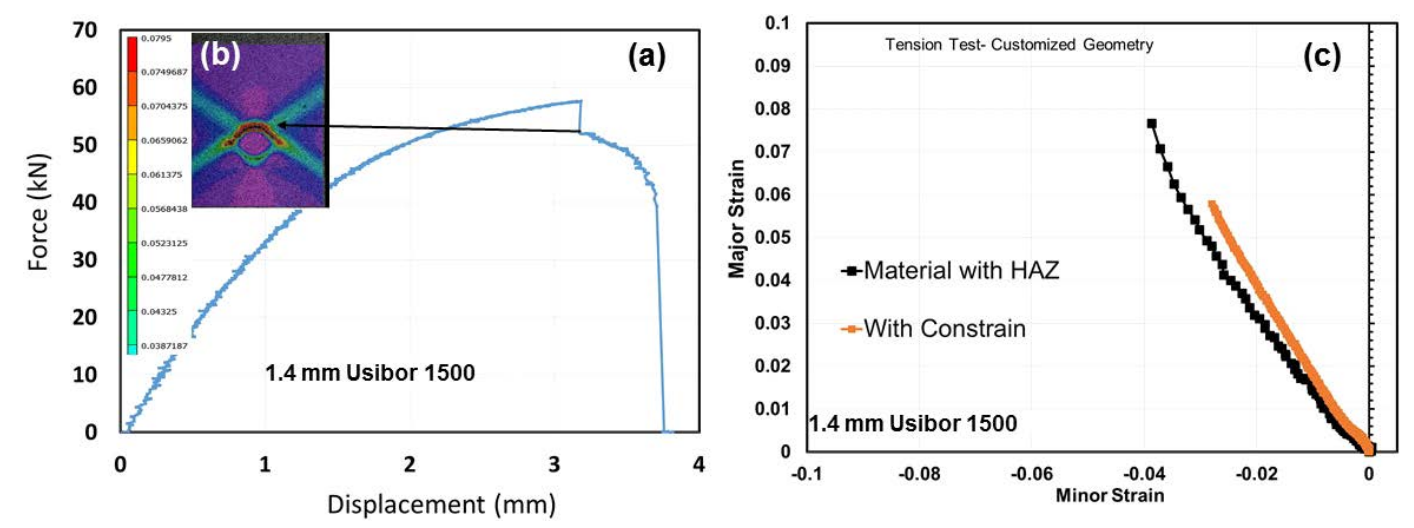

Fig. 13. For Usibor 1500 (a) Force vs displacement for double-layer welded stackup shown in Fig. 5(b), (b) engineering strain from map from DIC image after sharp force drop, and (c) Major strain vs minor strain for single sheet specimen (Fig. 5(a)) and double-layer welded stackup (Fig. 5(b)). (Online version in color.)

compared to the base metal $(470 \mathrm{HV})$ is 0.63 is close to the ratio of fracture strain of welded sample to base materials in plane strain state.

Although the strain path of the HAZ, as measured by $\mathrm{DIC}$, in plane strain is similar to base material until fracture point, the softened microstructure around nugget causes strain localization in HAZ. This results in premature failure as compared to material without HAZ softening. As the failure strain between the softened HAZ and base material is different, it is believed that the through-thickness strain path may not be similar for welded and base materials. In welded sample, significant necking occurs in the HAZ region where failure initiates, whereas strain is more uniform through thickness and the width of base material specimen.

The results of a single-sheet welded specimen after removing second sheet (e.g. Fig. 5(a)) show that the effect of HAZ softening on fracture strain can be investigated using simplified geometries after welding. In this configuration, two pieces of stackup (Fig. 8(b)) have been tested to determine the influence of nugget on failure, as it constrains the two sheets in the through thickness direction. During testing, strain was observed from outer surface of long sheet. Figure 13(a) shows force-displacement for a $5 \mathrm{~mm}$ nugget size. As Fig. 13(b) exhibits the strain localizes in softened HAZ in center and around nugget. The Force-displacement curve in Fig. 13(a) is similar to behavior observed in the single-sheet geometry (Fig. 6(a)). The load drop occurs suddenly because of strain localization in the HAZ and then displacement increases as crack propagate through HAZ and base material until full material separation. Major strain vs minor strain for single-sheet welded specimen (Fig. 5(a)) and stackup weld geometry (Fig. 5(b)), has been plotted in Fig. 13(c). The strain path is almost similar for both geometries, although, there is a slight difference in the fracture strain; 0.0746 for single-sheet specimen vs 0.06 for welded stackup. These results indicate that single-sheet welded specimen can be used for measurement of fracture strain, and this geometry can be used for other tests, such as biaxial or bending, whereas the welded stackup is not easy to use.

\subsection{Validation of Experimental Characterization for FEA Modeling}

A tensile sample with spot-weld, shown in Fig. 5(a), was chosen for comparison of experimental characterization and FEA modeling. Figure 14(a) shows the Finite element model of Usibor 1500, which has been simulated in LS-DYNA by shell element. FE model includes three regions, $5 \mathrm{~mm}$ diameter circle in center as nugget, $2 \mathrm{~mm}$ ring around nugget representative of HAZ region and the rest is base material. The GISSMO failure model was used to calculate damage in shell elements for the base material model and the HAZ shell elements. In the GISSMO model, damage is defined by a scalar value phenomenologically through a power law equation. The GISSMO damage model is a phenomenological formulation that allows for an incremental description of damage accumulation, including softening and failure. ${ }^{8)}$ For the HAZ ring, MAT123 with a single failure strain was used. The MAT123 material card is an elasto-plastic material available in LS_DYNA for shell and solid elements. Failure is based on effective plastic strain, plastic thinning or 

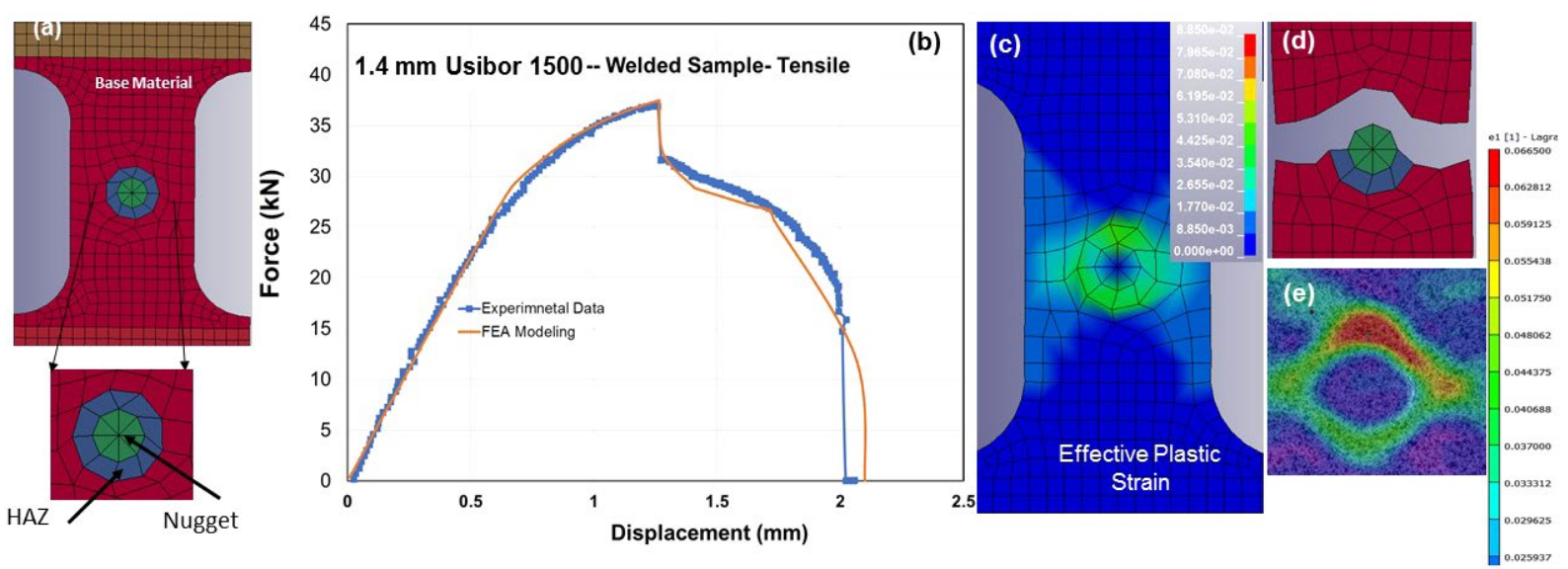

Fig. 14. For Usibor 1500 (a) Finite element model with $2 \mathrm{~mm}$ shell element size, (b) force-displacement from FE modeling and experimental measurement (c) effective plastic strain map right before failure, (d) \& (e) failure of samples predicted by FE model and experimental observation, respectively. (Online version in color.)

the major principal in-plane strain component. Experimental characterization in Fig. 12 shows that failure initiates at the location of the minimum hardness value in HAZ, so stressstrain data from the Gleeble sample presenting the minimum hardness in the HAZ (U600 in Fig. 2(a)) was used in model. The nugget has fully martensitic microstructure similar to the base metal, so similar material properties was used for both of them. Figure 14(b) shows the force-displacement from the experimental characterization (from Fig. 6(a)) and FEA modeling. Force-displacement from the FEA results are in good agreement with experimental characterization. As strain map in Fig. 14(c) shows, strain in the base material and the nugget is below 0.0177, while strain in the HAZ elements is inhomogeneous and is dependent on the force axis and the HAZ element location. The maximum strain in the HAZ element is two times higher than the strain in surrounding base material and nugget elements. Equivalent effective plastic strain for the first eliminated HAZ element is 0.09 . The significant difference between the strain of the HAZ elements and surrounding elements is due to much lower strength and strain hardening assigned to HAZ elements, which was based on the Gleeble experiments reported in Fig. 2. The element elimination in MAT123, which has been used for the HAZ elements, occurs when strain in element reaches to a single value, and it results in sharp drop in load drop. These results indicate the plastic deformation and strain in HAZ element results in failure strain based on experimental input parameters. Figure 14(d) shows the FEA model after failure which HAZ elements have been eliminated first, and then propagates through base metal. This failure mode is close to what has been observed form experimental characterization, shown in Fig. 14(e).

The strain path of the HAZ in spot-welded samples can change dependent on stackup configuration, component, load flow and impact type (e.g. side vs front) during crash test. Strain path in HAZ obtained under uniaxial tensile test might happen in case of spot weld shear loading modes, such as tension-shear with minimum HAZ and material bending. However, spot weld failure in the HAZ is usually observed in coupon tests with cross-tension loading modes in which the HAZ experiences bending deformation. Figure 15(a) shows the image of cross-tension sample after failure, which shows a button pull out mode and failure

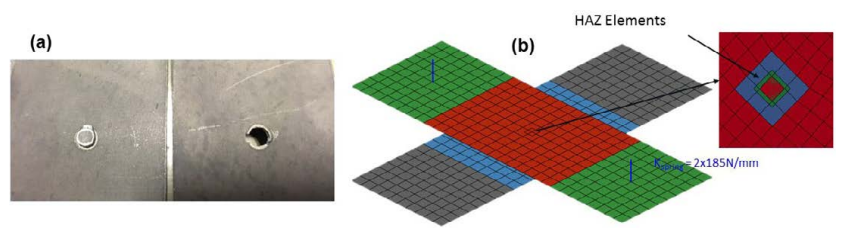

Fig. 15. (a) Image of cross-tension after failure showing plug failure from HAZ and (b) LS-DYNA model with $3 \mathrm{~mm}$ element size and 1-HEX solid element for weld. (Online version in color.)

occurring in HAZ. Figure 15(b) shows the LS-DYNA model which has a $3 \mathrm{~mm}$ element size for base material and HAZ is modeled as separate set of elements around nugget (indicated by arrow). The spot weld has been modeled by 1 HEX solid element, and solid element nodes are connected to HAZ elements. Fracture strain as a function of stress triaxiality which is mostly used for base material is not appropriate for HAZ, because strain path within HAZ is not uniform and consequently stress triaxiality can change within HAZ. In addition, as shown in Fig. 11, fracture strain is almost independent of strain path for $3 \mathrm{~mm}$ element size, so, MAT123 was used for HAZ elements; using a fracture strain value of 0.037 in Table 2 for plane strain state.

Figure 16(a) shows force vs displacement curves for experiment and FEA modeling. As seen, there is a good agreement between experiment and FEA modeling in case of total displacement as well as load drop. As FEA model inside Fig. 16(a) shows, the failure has occurred in HAZ element. Figures 16(b) and 16(c) show effective plastic strain and stress triaxiality for eliminated HAZ element as a function of time. Effective strain in time of fracture is 0.037 , indicated by dashed lines, which is very good agreement with experimental results measured by DIC and presented in last row of Table 2. Stress triaxiality in eliminated HAZ element in time of fracture is 0.58 , which is close to plane strain state due to bending of HAZ element during crosstension test. These results conclude that fracture strain in HAZ element can be measured with proposed samples and gauge length. 

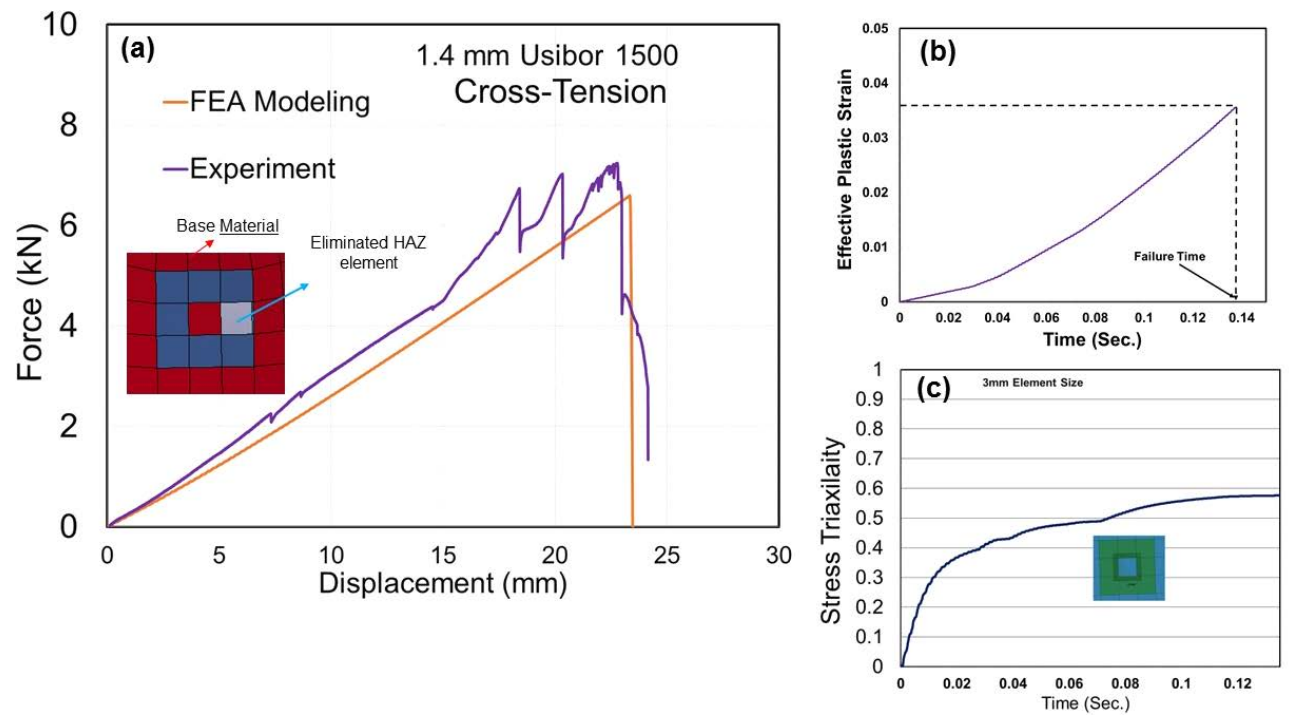

Fig. 16. (a) Force displacement for experimental test and FEA modeling using LS-DYNA, (b) fracture strain and (c) stress triaxiality for eliminated HAZ element as a function of time. (Online version in color.)

\section{Conclusions}

Advanced characterization of HAZ has been done by two methods. First method is characterization of different extent of softening in HAZ using specimens which have been heat treated by Gleeble. Second method is the measurement of fracture strain using welded samples, either single-sheet after removing second sheet or double-layer stackup specimens. The following summaries can be concluded from this study:

(1) Uniaxial tensile stress-strain curves for Gleeble specimens show that slight tempering at low temperature can change strain hardening, but strain hardening does not change with higher tempering at higher temperature.

(2) The non-linear dependency of yield stress from base metal to significant tempering for Gleeble specimens was observed. Yield stress increases for lower tempering temperature as compared to base material, then decreases with increasing tempering temperature. While strain hardening decreases with minor tempering, then it is almost constant for higher tempering temperatures. This is contrary to what is calculated using ratio of HAZ hardness to base material. Scaling of base material stress-strain curve will reduce flow stress, including yield stress and UTS, while strain hardening is kept constant.

(3) Fracture strain of Gleeble specimens change significantly for tempering temperatures above $400^{\circ} \mathrm{C}$. Fracture strain is almost constant for tempering temperatures below $400^{\circ} \mathrm{C}$, whereas strain hardening reduces considerably at tempering temperatures below $400^{\circ} \mathrm{C}$.

(4) Investigation of plastic deformation and strain measurement of welded samples using DIC show that strain is localized in HAZ, due to the presence of HAZ softening. Uniaxial tensile and notch geometries were used to measure fracture strain of HAZ in welded samples. Both geometries result in similar strain paths in the weld HAZ and base material.

(5) Fracture strain has a weak dependence on strain path for welded samples, whereas it changes significantly with strain path for base material.
(6) The difference between testing of welded single sheet and full stackup welded specimens is negligible, therefore single sheet welded specimens may be used to characterizer bending, biaxial stretch and other out-of-plane mechanical properties.

(7) FEA results of welded tensile sample and crosstension tests using input data from Gleeble samples and tested welds show a good correlation to experimental characterization with respect to failure load, displacement and failure location.

\section{Acknowledgements}

The authors would like to acknowledge Hong Zhu for discussion related to strain measurement using DIC, and ArcelorMittal leadership for supporting and allowing us to publish this work.

\section{REFERENCES}

1) N. Khandoker and M. Takla: Mater. Des., 54 (2014), 323.

2) F. Schneider and N. Jones: Int. J. Mech. Sci., 45 (2003), 2061.

3) E. Biro, J. R. Mcdermid, J. D. Embury and Y. Zhou: Metall. Mater. Trans. A, 41A (2010), 2348.

4) E. Biro, S. Vignier, C. Kaczynski, J. R. Mcdermid, E. Lucas, J. D. Embury and Y. N. Zhou: ISIJ Int., 53 (2013), 110.

5) E. Biro and H. Ghassemi-Armaki: Sheet Metal Welding Conf. XVII, American Welding Society, FL, (2016), 1.

6) H. Ghassemi-Armaki, S. Bhat, S. Kelley and S. Sadagopan: Weld. J., 96 (2017), 104.

7) D. P. Noorman: 9th European LS-DYNA Conf., DYNAlook, Germany, (2013), 1.

8) LS-DYNA Keyword User's Manual Volume II, Livermore Software Technology Corporation (LSTC), Livermore, California, (2015), 567.

9) S. Patil: Ph.D. Thesis, Wichita State University, (2016), http:// soar.wichita.edu/bitstream/handle/10057/11107/d14027.pdf? sequence $=1 \&$ isAllowed $=y,($ accessed $2016-7-1)$

10) T. K. Eller, L. Greve, M. Andres, M. Medricky, H. J. M. Geijselaers, V. T. Meinders and A. H. van den Boogaard: J. Mater. Process. Technol., 234 (2016), 309.

11) S. Burget and S. Sommer: LS-DYNA Forum, DYNAmore GmbH, Stuttgart, (2012), 63.

12) S. Burget and S. Sommer: 13th Int. Conf. on Fracture, The Chinese Society of Theoretical and Applied Mechanics, Beijin, (2013), 16.

13) AWS D8.9M: 2012, Test Methods for Evaluating the Resistance Spot Welding Behavior of Automotive Sheet Steel Materials.

14) J. Dykeman, S. Malcolm, B. Yan, J. Chintamani, G. Huang, N. Ramisetti and H. Zhu: SAE Technical Paper, SAE, Warrendale, PA, (2011), 1058. 